\title{
A Numerical Study of a Newly Developed of Savonius Wind Turbine Style on Increasing the Performance of Savonius Wind Rotor
}

\author{
Youssef Kassem, Hüseyin Çamur \\ Department of Mechanical Engineering, Faculty of Engineering, Near East University, Nicosia, Cyprus
}

Email address:

yousseuf.kassem@neu.edu.tr (Y. Kassem), huseyin.camur@neu.edu.tr (H. Çamur)

\section{To cite this article:}

Youssef Kassem, Hüseyin Çamur. A Numerical Study of a Newly Developed of Savonius Wind Turbine Style on Increasing the Performance of Savonius Wind Rotor. American Journal of Modern Energy. Vol. 3, No. 6, 2017, pp. 115-120. doi: 10.11648/j.ajme.20170306.11

Received: October 5, 2017; Accepted: October 19, 2017; Published: November 23, 2017

\begin{abstract}
In the present study, a new model of Savonius wind turbine has been designed to increase the low performance of the Savonius wind rotor, a type of vertical-axis wind rotor, and the effect of wind speed on the static rotor performance has been analyzed numerically using solid-work flow simulation (SWFS). SWFS is based on the Reynolds Averaged NavierStokes (RANS) equations with the standard $k-\varepsilon$ turbulence model. These equations were solved by a finite volume discretization method. Further, the effects of rotor geometries and end plate on static torque are also discussed. In order to clarify the new designed of the rotor, static torque was measured with various blade sizes and end plate shape. From the study, found that the use of both upper and lower end plats significantly increase the torque by $40 \%$ compared with no end plates. Additionally, it was also observed that the torque of rotors increases proportionally to blade size and end plate shapes. Moreover, the results showed that model 2 has produced more torque compared to other models.
\end{abstract}

Keywords: Savonius Wind Turbine, SWFS, Vertical Axis Wind Turbine, Torque

\section{Introduction}

The Savonius rotor is a novel fluid mechanical device that has been studied by numerous investigators since the 1920s. Applications for the Savonius rotor have included pumping water, driving an electrical generator, providing ventilation (attic and vehicular applications), and providing water agitation to keep stock ponds ice free during the winter. [1-4].

Savonius turbine, a vertical axis wind turbine though with high starting torque and reasonable peak power output [5]. The characteristic performance of two and three bucket Savonius rotor has been carried out in wind tunnel tests, field experiments and numerical studies to evaluate the effect of aspect ratio, blades overlap and gap, effect of adding end extensions, end plates and shielding. [6-9]

Bhaskar and Gaurav [10] made numerical analysis using (computational fluid dynamic (CFD) software ANSYSFLUENT) on a two-Bladed Savonius Rotor, a study on drag and torque coefficient curves at different rotor blade angles at each $10^{\circ}$ interval was carried out. These curves show that the drag and torque coefficients reached its maximum at $0^{\circ}$ and $30^{\circ}$ rotor blade angles respectively.
Konrad et al. [6] investigated numerically, the running performance of Bach-type and Elliptical designs Savonius wind turbine rotor, using ANSYS $\mathrm{CFX}^{1}$ (commercial, finite volume, CFD code (ANSYS/CFX) is used for 3D component of the model). The running performance of the Savonius rotor, such as the torque coefficient, is obtained for various tip speed ratios. It was discovered that the Bach-type has a maximum torque and power coefficient whilst the Elliptical Savonius turbine has better performance in terms of power characteristics.

Keum el at. [7] experimentally studied the effect of end plates with various shapes and size on the aerodynamic performance of helical Savonius wind turbine with twist angle and two semi-circular buckets. The results showed the power coefficient increased linearly in proportion to the area of the end plate.

Zied et al. [8] studied numerically and experimentally the bucket design effect on the turbulent flow around

\footnotetext{
${ }^{1}$ Reference [11] describes the meaning of ANSYS CFX.
} 
unconventional Savonius wind rotors. The software "Solidworks Flow simulation" used to characterize the flow characteristics in different transverse and longitudinal planes. The distribution of the turbulent kinetic energy, distribution of the dynamic pressure, distribution of the total pressure, distribution of the turbulent viscosity, the distribution of the vortices and velocity profiles is measured experimentally and numerically respectively. The good agreement between numerical and experimental results confirms the validity of the numerical method.

Sobhi et al. [9] studies numerically and experimentally the effect of multi-stage on the performance of a Savonius rotor. The software "SolidWorks Flow Simulation" has been used to present the local characteristics in different transverse and longitudinal planes. The experimental and numerical results are compared in terms of velocity profile, dynamic torque coefficient and power coefficient.

This study aims to numerically investigate double semicylindrical blade and end plate effects using various shapes and sizes of blades and end plates on the aerodynamic performance of the Savonius wind turbine. This is the first study to conduct such an investigation.

\section{Principles of Savonius Rotor Wind}

\section{Turbine}

A Savonius rotor is a drag-type turbine $[12,13]$. In the simplest form, a Savonius rotor consists of two half-cylinder sections fixed to a half in the form that their cross section makes a letter " $S$ " as shown in Figure 1. In operation, one blade captures the wind while the other moves against the wind, thus opposing the wind. The net torque to rotate the turbine is the torque from the blade capturing the wind energy minus the resistive torque that the other blade receives against moving. This is the case for all the drag type turbines. One can add more half cylinders on the shaft in order to increase the capacity of wind capture. It will also increase the length of the cylindrical sections, provided all the sections are aligned. Alternatively a second set can be installed at $90^{\circ}$ from the first half cylinders. This adds to uniformity of rotational torque on the half of the shaft since with only two half cylinders, the absorbed power pulsates making it uniform as the rotor turns.

A Savonius rotor has about half of the power capture capability of the other (lift-based) turbines; its power coefficient at optimum performance is about half of the magnitude that can be achieved by a propeller turbine. In order to increase the power capture capability of a Savonius turbine, certain modifications to the basic design have been proposed. Firstly, is to create a gap in the structure where the two halves cylinders are joined. This allows the air to pass through this gap from the segment capturing wind to the segment opposing wind, as depicted in Figure 1. The advantage of the twofold: wind is not trapped in the capturing blade and has a more steady flow, and the opposing blade has an extra force to help it push the air. [13]

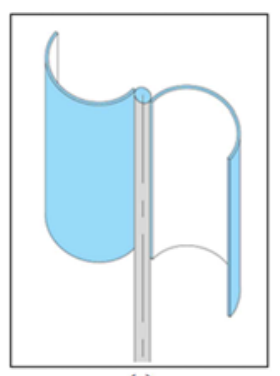

(a)

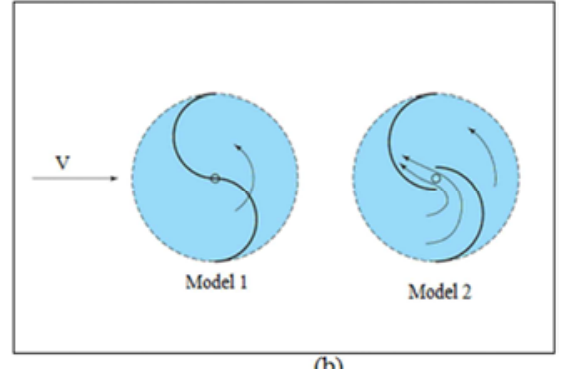

(b)
Figure 1. (a) Construction of Savonius rotor, (b) Alternative designs for Savonius rotor.

\section{Present Study}

The two models of Savonius turbine used in this study are shown in Figure 2. The configuration of model 1 and model 2 of Savonius wind turbine with four semi-cylindrical and the main shaft without or with overlap, i.e. without or with a separation gap, respectively are shown in Figure 2.

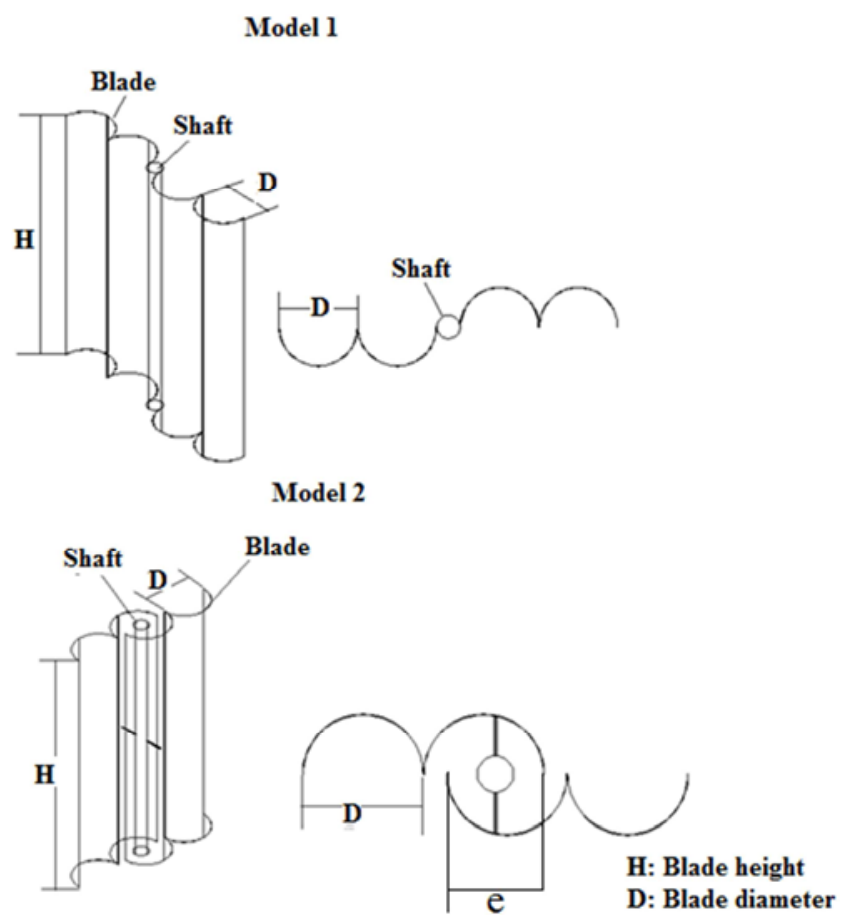

Figure 2. Models of Savonius turbine.

Table 1 lists the details of blade diameter, blade height, and shaft diameter and blade thickness. The blades were made from ABS (Acrylonitrile Butadiene Styrene) because the simulation results will compare with experimental results in the future. The Experiment will be done by using subsonic wind tunnel $(30 \mathrm{~cm} \times 30 \mathrm{~cm})$. Therefore, the dimensions of the Double semi-cylindrical Savonius wind turbine are chosen according to subsonic wind tunnel $(30 \mathrm{~cm} \times 30 \mathrm{~cm})$. 
Table 1. Geometric parameters of new geometry of Savonius wind turbine.

\begin{tabular}{|c|c|c|c|c|c|}
\hline Designation of Savonius rotors & Blade diameter [mm] & Blade height [mm] & Shaft diameter [mm] & Blade thickness [mm] & Gap [mm] \\
\hline \multicolumn{6}{|l|}{ Model 1} \\
\hline WOG\#1 & 20 & 100 & 12 & 0.008 & - \\
\hline WOG\#2 & 30 & 150 & 12 & 0.008 & - \\
\hline WOG\#3 & 40 & 200 & 12 & 0.008 & - \\
\hline \multicolumn{6}{|l|}{ Model 2} \\
\hline WG\#1 & 20 & 100 & 12 & 0.008 & 16 \\
\hline WG\#2 & 30 & 150 & 12 & 0.008 & 16 \\
\hline WG\#3 & 40 & 200 & 12 & 0.008 & 16 \\
\hline WOG & Without Gap & & WG & With Gap & \\
\hline
\end{tabular}

The Models of Savonius wind turbines were designed as shown in Figure 3. The end plates were fabricated from ABS plate of $0.008 \mathrm{~mm}$ thickness. To study efficiency, according to endplate shape, the diameter of the end plate was the same as the diameter of wind turbine blade.

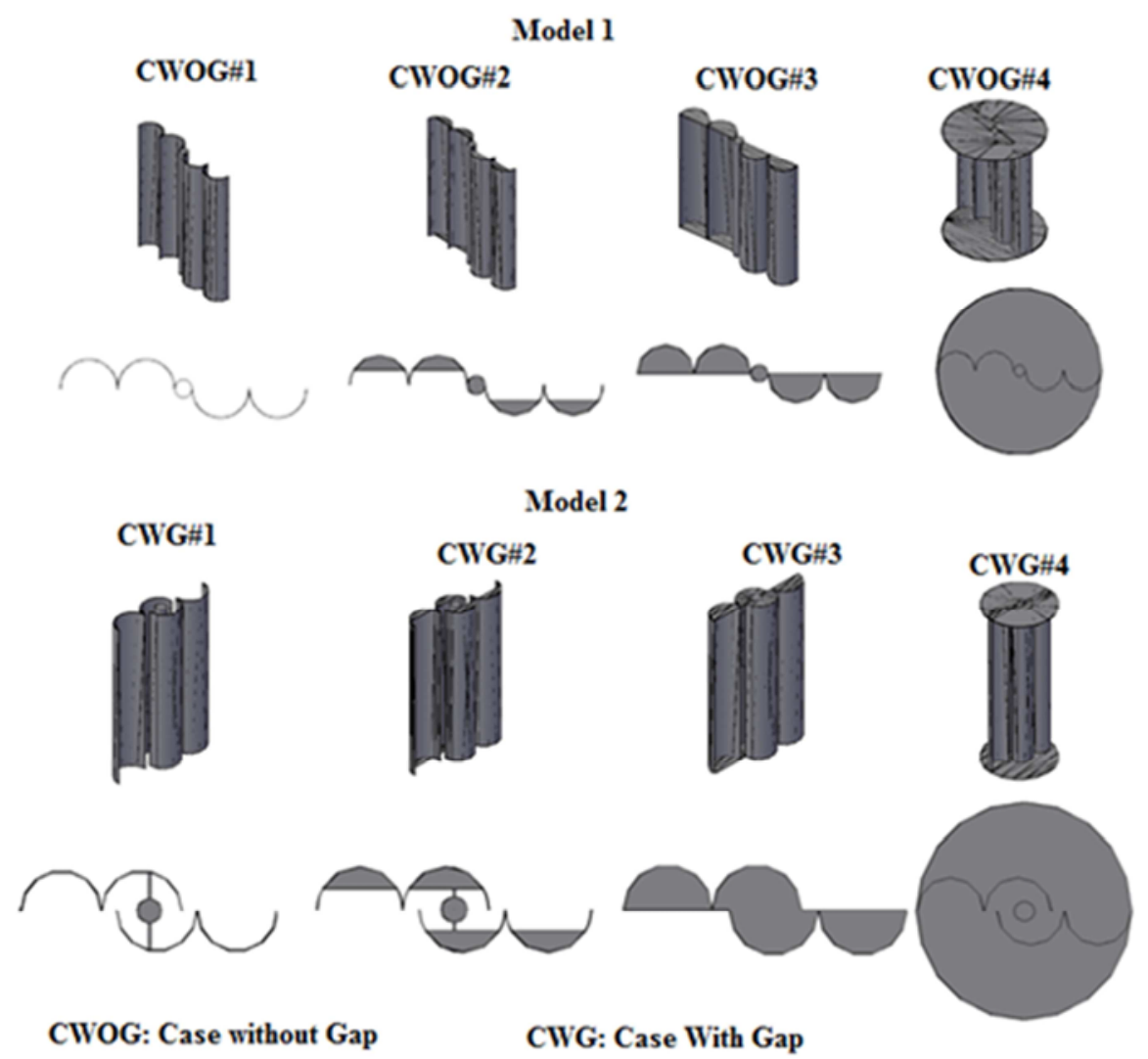

Figure 3. Views of models of Savonius wind turbines with various sizes of end plates.

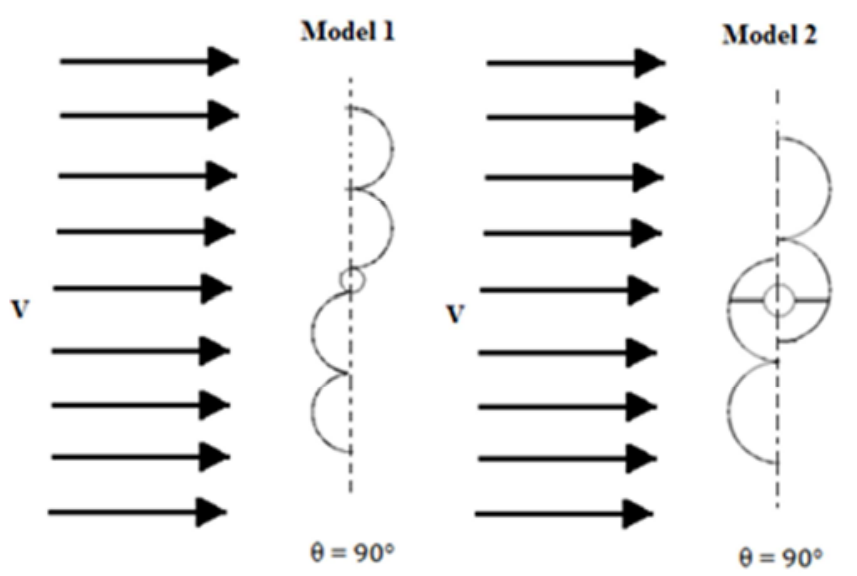

Figure 4. Rotor position $\theta=90^{\circ}$

\section{Results and Discussions}

The models of turbine are tested for various wind speed, V, 4, 6 and $8 \mathrm{~m} / \mathrm{s}$ to determine the static torque. A static torque value for each model has been measured at the same position of rotor angle $\theta\left(\theta=90^{\circ}\right)$ in the numerical study as shown in Figure 4.

Figures 5, 6 and 7 show the variation of torque with wind speed of model 1 and 2 of Savonius wind turbine (without gaps, WOG, and with a gap, WG). It shows that for a constant blade height, different blade diameter, and plate size the torque is proportional to wind speed and blade sizes. However, increasing the wind speed and size of the blade lead to an increase the torque wind turbine.

Additionally, it can be observed from these figures, the 
increase of end plate size is significantly increasing the torque by $20 \%$ approximately compared with no end plate. And, the use of both upper and lower circular end plate size is increasing the torque and drag force by $40 \%$ compared with no end plate.

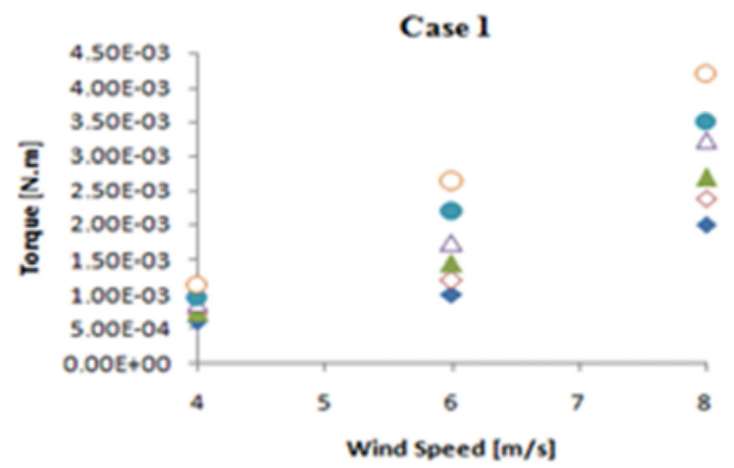

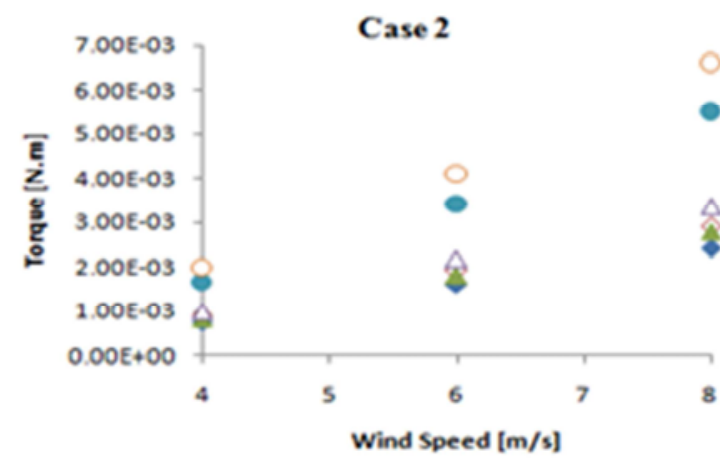

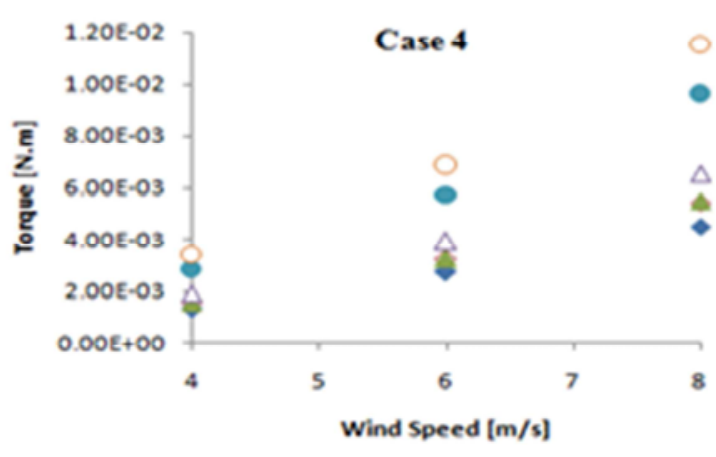

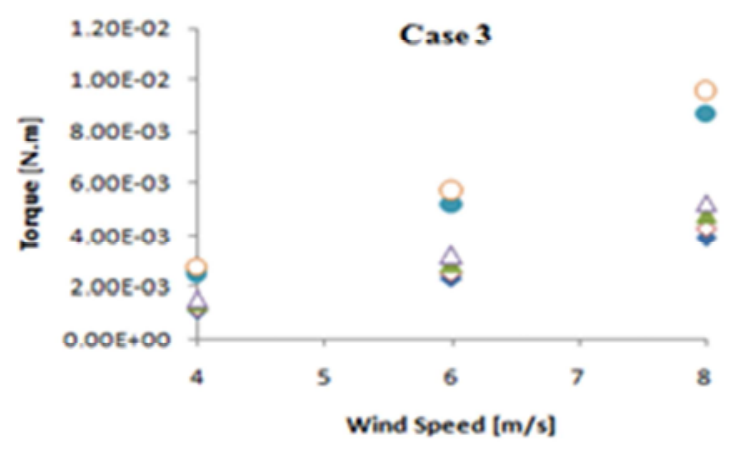

-WOG, D= $20 \mathrm{~mm}$

W $W$, $D=20 \mathrm{~mm}$

$\triangle W O G, D=30 \mathrm{~mm}$ $\triangle W G, D=30 \mathrm{~mm}$

-WOG, $D=40 \mathrm{~mm}$

OWG, $D=40 \mathrm{~mm}$

Figure 5. Torque versus wind speed for different models at constant blade height, $H=100 \mathrm{~mm}$.
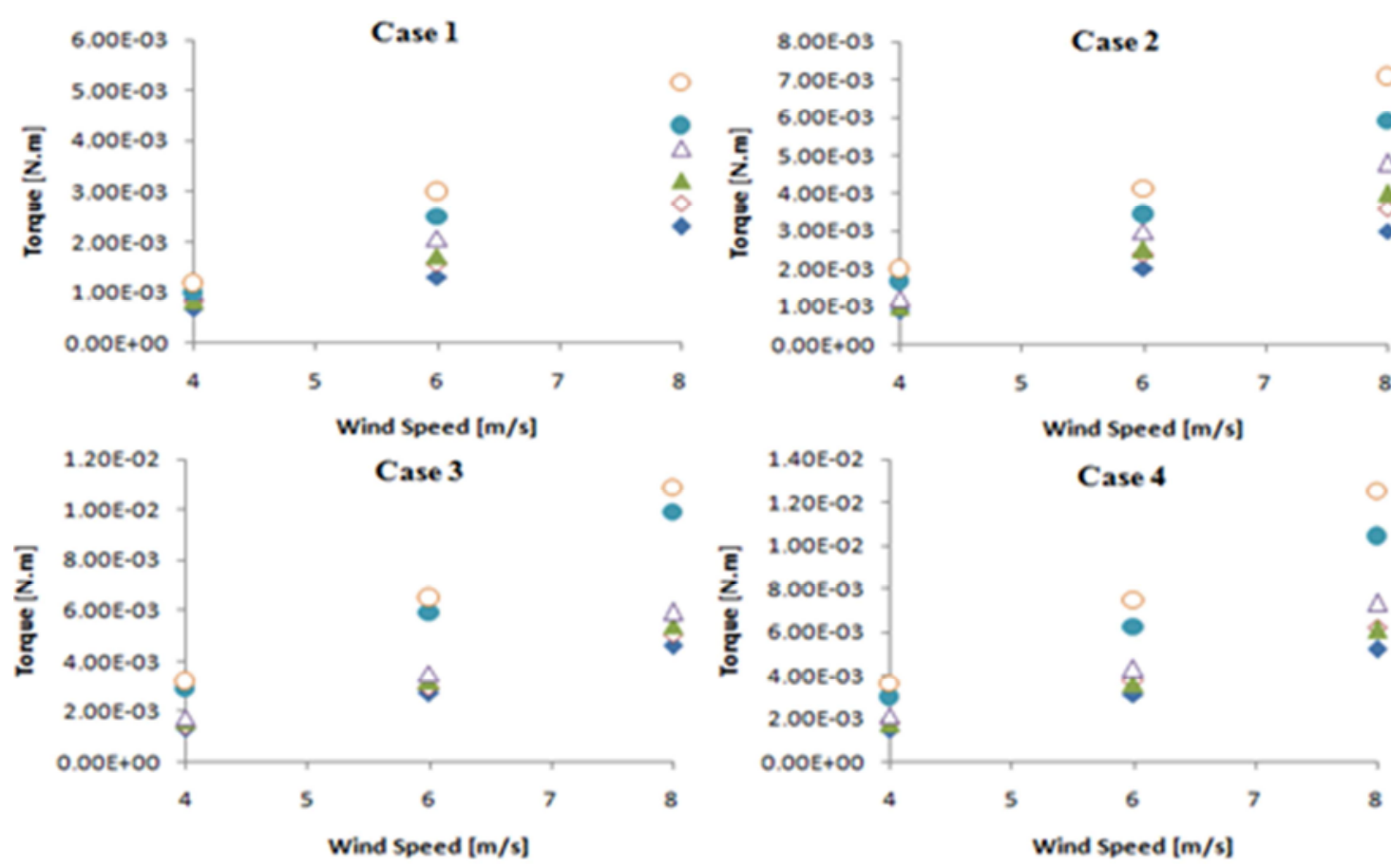

- WOG, D= $20 \mathrm{~mm}$

-WG, D $=20 \mathrm{~mm}$

$\triangle W O G, D=30 \mathrm{~mm}$

$\triangle W G, D=30 \mathrm{~mm}$

- WOG, $D=40 \mathrm{~mm}$

OWG, D $=40 \mathrm{~mm}$

Figure 6. Torque versus wind speed for different models at constant blade height, $H=150 \mathrm{~mm}$. 

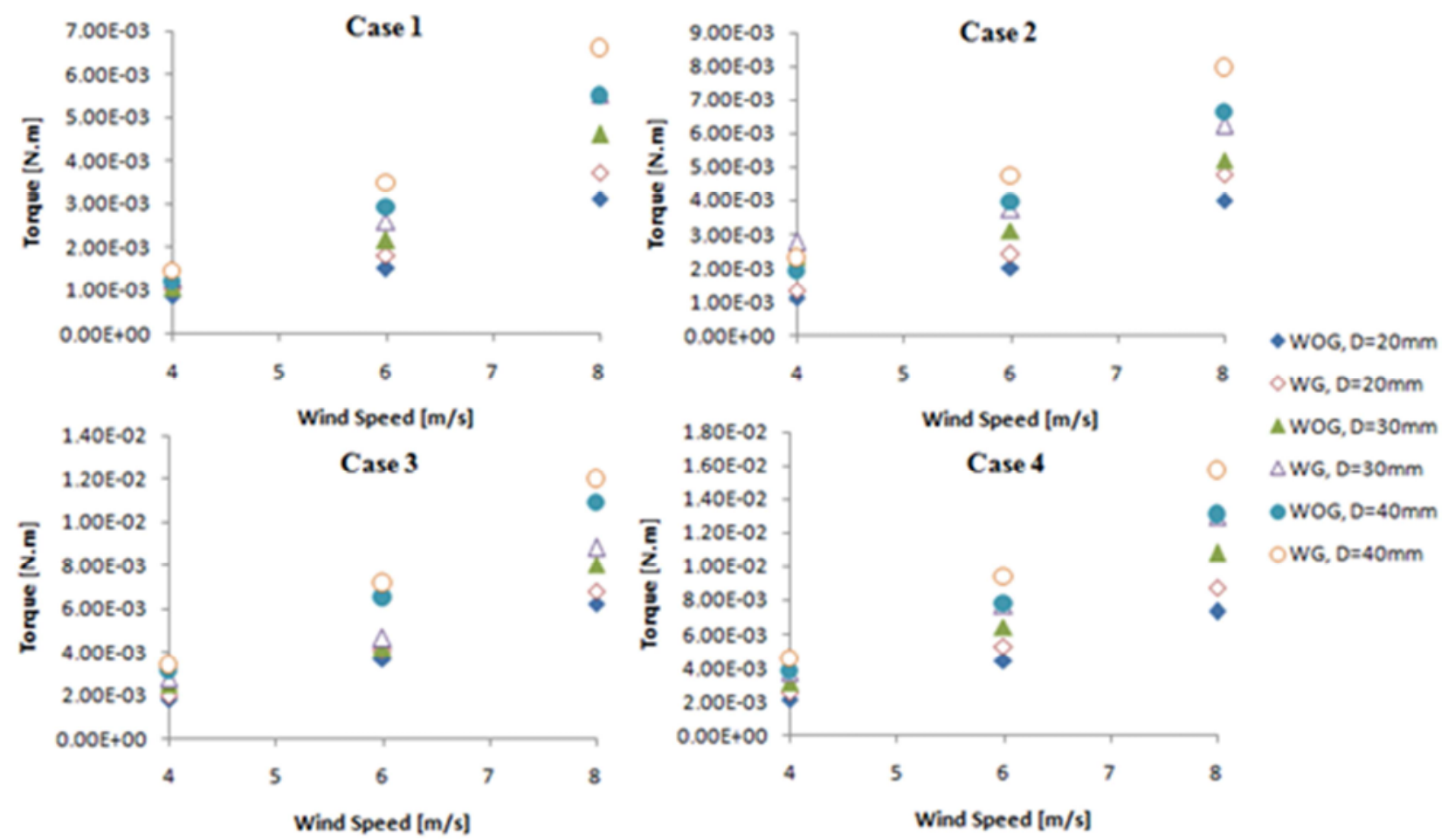

Figure 7. Torque versus wind speed for different models at constant blade height, $H=200 \mathrm{~mm}$.

\section{Conclusions}

In conclusion of this study, the effect of blade size and the end plate size of new models of Savonius wind turbine was studied numerically by using Flow Simulation Solid-Work. Additionally, the objective of this study was to increase the performance of the Savonisu wind turbine. The Static torque of the new models of Savonius wind turbine was tested at various wind speeds, blade sizes and end plate shapes. From this study, the following conclusions are summarized:

a. The study showed that the torque increase with the increasing of blade size, end plate size and wind speed.

b. Size of blades and end plate shapes influenced the torque of the rotor of Savonius models. The blade of diameter $40 \mathrm{~mm}$ and height $200 \mathrm{~mm}$ produced more torque than other blade size.

c. Size of end plate directly affects the torque of the rotor of the turbine. The upper and lower circular end plate produce more torque compared to other end plate size. This may be due to the drag force affected on the rotor in the upper and lower circular end plate case is higher than those for other cases.

d. It can be observed from the results, the increase of end plate size is significantly increasing the torque and drag force by $20 \%$ compared with no end plate. And, the use of both upper and lower circular end plate size is increasing the torque and drag force by $40 \%$ compared with no end plate.

\section{Future Works}

In the future, the effect of the flow field around the new models of Savonius turbine will study numerically and experimentally using a subsonic wind tunnel. In addition, the torque and mechanical power of the new models of Savonius turbine will be examined numerically and experimentally and compare with a traditional Savonius turbine to obtain the increase performance of the new model.

\section{References}

[1] Modi, V. J., Roth, N. J., \& Pittalwala, A. (1983). Blade Configurations and Performance of the Savonius Rotor With Application to an Irrigation System in Indonesia. Journal of Solar Energy Engineering, 105 (3), 294. doi: $10.1115 / 1.3266381$.

[2] Clark, R., Nelson, V., \& Barieau, R. (1980). Wind turbines for irrigation pumping. Wind Energy Conference. doi:10.2514/6.1980-639.

[3] Modi, V., Fernando, M., \& Yokomizo, T. (1998). An integrated approach to design of a wind energy operated irrigation system. 1998 ASME Wind Energy Symposium. doi:10.2514/6.1998-41.

[4] Vishwakarma, R. (1999). Savonius rotor wind turbine for water pumping - an alternate energy source for rural sites. Journal of Institution of Engineers (India), 79.

[5] Reupke, P., \& Probert, S. (1991). Slatted-blade Savonius wind-rotors. Applied Energy, 40 (1), 65-75. doi:10.1016/03062619 (91)90051-x.

[6] Ushiyama I, Nagai H, \& Mino M. (1982). The optimum design configurations of Savonius wind turbines. In: Proceedings of 17 th intersociety energy conversion engineering conference, 2096-101. 
[7] Sayers, A. T. (1985). Blade Configuration Optimization and Performance Characteristics of a Simple Savonius Rotor. Proceedings of the Institution of Mechanical Engineers, Part A: Power and Process Engineering, 199 (3), 185-191. doi:10.1243/pime_proc_1985_199_023_02.

[8] Sheldahl, R., Feltz, L., \& BLACKWELL, B. (1978). Wind tunnel performance data for two- and three-bucket Savonius rotors. Journal of Energy, 2(3), 160-164. doi:10.2514/3.47966.

[9] Modi, V., \& Fernando, M. (1989). Modi VJ, Fernando MSUK. On the performance of the Savonius wind turbine. ASME Journal of Solar Energy Engineering, 111, 71-81.

[10] Choudhury, B., \& Saraf, G. (2014). Computational Analysis of Flow around a Two-Bladed Savonius Rotor. ISESCO JOURNAL of Science and Technology, 10 (17), 39-48.

[11] Kacprzak, K., Liskiewicz, G., \& Sobczak, K. (2013). Numerical investigation of conventional and modified Savonius wind turbines. Renewable Energy, 60, 578-585. doi:10.1016/j.renene.2013.06.009.
[12] Jeon, K. S., Jeong, J. I., Pan, J., \& Ryu, K. (2015). Effects of end plates with various shapes and sizes on helical Savonius wind turbines. Renewable Energy, 79, 167-176. doi:10.1016/j.renene.2014.11.035.

[13] Driss, Z., Mlayeh, O., Driss, S., Driss, D., Maaloul, M., \& Abid, M. S. (2015). Study of the bucket design effect on the turbulent flow around unconventional Savonius wind rotors. Energy, 89,708-729. doi:10.1016/j.energy.2015.06.023.

[14] Frikha, S., Driss, Z., Ayadi, E., Masmoudi, Z., \& Abid, M. S. (2016). Numerical and experimental characterization of multistage Savonius rotors. Energy, 114, 382-404. doi:10.1016/j.energy.2016.08.017.

[15] Sun, D. W. (2007). Computational fluid dynamics in food processing. Boca Raton, FL: Taylor \& Francis.

[16] Sathyajith, M. (2014). Wind Energy: Fundamentals, Resource Analysis and Economics. Berlin: Springer Berlin.

[17] Hemami, A. (2012). Wind turbine technology. Clifton Park, NY: Delmar, Cengage Learning. 